Asian J. Med. Biol. Res. 2020, 6 (2), 176-186; doi: 10.3329/ajmbr.v6i2.48048

\author{
Asian Journal of \\ Medical and Biological Research \\ ISSN 2411-4472 (Print) 2412-5571 (Online) \\ www.ebupress.com/journal/ajmbr
}

\title{
Article \\ Association of oxytocin receptor gene polymorphisms with autism spectrum disorder in Bengali of Bangladesh population
}

\author{
Mahadia Kumkum ${ }^{1 a}$, Lolo Wal Marzan ${ }^{1 a^{*}}$, Shahin Akter $^{1}$, Soma Chowdhury Biswas ${ }^{2}$, Mahmood Ahmed \\ Chowdhury $^{3}$ and Mohammad Afzal Hossain ${ }^{4}$ \\ ${ }^{1}$ Department of Genetic Engineering and Biotechnology, Faculty of Biological Sciences, University of \\ Chittagong, Chittagong-4331, Bangladesh \\ ${ }^{2}$ Department of Statistics, Faculty of Sciences, University of Chittagong, Chittagong-4331, Bangladesh \\ ${ }^{3}$ Institute of Autism and Child Development Centre, Chattogram Maa-O-Shishu General Hospital, Agrabad, \\ Chittagong-4100, Bangladesh \\ ${ }^{4}$ Department of Psychology, Faculty of Biological Sciences, University of Chittagong, Chittagong-4331, \\ Bangladesh
}

${ }^{\mathrm{a}}$ Shared first author

"Corresponding author: Professor Dr. Lolo Wal Marzan, Department of Genetic Engineering and Biotechnology, Faculty of Biological Sciences, University of Chittagong, Chittagong-4331, Bangladesh. Phone: +88-031-2606001-10, Fax: +88-031-2606145; E. mail: marzan.geb@cu.ac.bd

Received: 21 March 2020/Accepted: 20 May 2020/ Published: 30 June 2020

\begin{abstract}
Autism spectrum disorder (ASD) is a group of sex-biased neurodevelopmental disorders characterized by core deficits in social interaction, communication and behaviors. Several lines of evidence indicate that oxytocin signaling through its receptor (OXTR), is vital in a wide range of social behaviors and role of $O X T R$ polymorphism in ASD development has also been established in several populations. Therefore, an attempt was taken to determine whether genetic variations in the oxytocin signaling system contribute to ASD susceptibility in a part of Bangladeshi (BEB) population. We have investigated the role of OXTR polymorphisms (rs53576, rs2254298, rs2228485 and rs237911) in ASD development through PCR-RFLP method, based on case studies. A significant frequency $(\mathrm{p}=0.027)$ for OXTR 'rs53576AA' risk genotype was found to be associated with ASD which is consistent with the previous study in Chinese but Caucasian and Japanese population. Besides, no significant association has been found for other OXTR variants (rs2254298, rs2228485 and rs237911) in this study. Understanding of these significant association with ASD development could be open a new clue aimed at clinical marker development for ASD diagnosis and treatment in future.
\end{abstract}

Keywords: autism spectrum disorder (ASD); OXTR; rs53576; polymorphism; BEB population

\section{Introduction}

Autism spectrum disorder (ASD) is a combination of neurodevelopmental disorders (Norbury et al., 2013) portrayed by developmental delays, impaired functioning in social and communicative skills and the presence of restricted, repetitive behavior (Volkmar et al., 2004) and there is neither any specific cause nor cure known for this condition because of heterogenic as well as complex nature of it (Harris, 2016). The establishment of social relationships and social communication is a fundamental developmental task of infancy. On 26th April 2018, the Central for Disease Control's (CDC) Autism and Developmental Disabilities Monitoring (ADDM) network updated the prevalence rate of ASD in United States as 1 in 59 children (1.7\%) which is higher than the previous estimate of $1.5 \%$ or 1 in 68 children released in 2016 (CDC, 2018). ASD has already been identified as a burden of diseases in Bangladesh, and it has been assumed that the magnitude is high which makes it the 9th 
top most countries of the world (Daily Prothom Alo, 2018).

Over the last half-century, varying conceptual models for etiologic factors in autism spectrum disorder (ASD) have been proposed, most emphasizing single cause hypotheses. But based on more than one decade of research; currently, we know that the etiology of ASD is complex, heterogeneous, and multifactorial (Betancur, 2011). Researchers have estimated the heritability of ASD at 55-80\%, indicating that genetic influences are responsible for most of its etiology (Lichtenstein et al., 2010; Freitag, 2007). One of the prime deficits in ASD is the social deficit; it is not surprising that many researchers have attempted to find if there is any causative link between oxytocin and ASDs. Oxytocin (OXT) is a nine-amino-acid peptide hormone which exerts its effect by activating its specific G-protein-coupled oxytocin receptor (OXTR) to relays the messages to downstream effectors and plays a prominent role in social behavior across species (Hollander et al., 2007). Oxytocin hormone is known to play a vital role in the regulation of social recognition, affiliation, bonding, and attachment (Friedlander et al., 2019; Hollander et al., 2007). Animal studies have shown that oxytocin and vasopressin help regulate the social behavior of prairie voles, especially the formation of partner preference (Heinrichs et al., 2009). Notably, OXTR gene knockout mice models manifest impaired social memory while parturition was mostly unaffected (Takayanagi et al., 2005; Ferguson et al., 2000). Employing an intranasal administration paradigm revealed that OXT commonly stimulates all social cognitive functions, including the demonstration of a good emotional bond between parents and neonate (Ebstein et al., 2009). Numerous genetic studies in humans and animals have reported that associations between polymorphisms on the OXTR gene and phenotypes are related to social cognition (Tops et al., 2019; Ribeiro et al., 2018; Gong et al., 2017), affiliation, perspective taking and sociability in ASD (Reuter et al., 2017; Parker et al., 2014; Skuse et al., 2014). In the Chinese Han population, the OXTR-SNPs rs53576 and rs2254298 found to be significantly associated (Wu et al., 2005), but no association was found for rs2228485 and rs237911 in the studied ASD population. This OXTR-ASD association was also supported by a meta-analysis (LoParo and Waldman, 2015), and the role of the OXTR polymorphism in ASD development has also been established in several populations (Montag et al., 2017; Lakatosova et al., 2013; Campbell et al., 2011).

The availability of genetic testing on the basis of genetic risk factor, the number of potentially critical genetic findings would outstrip the capacity for reliable and valid interpretation and genetic counseling also can rapidly emerging insights into the neurobiology underlying autism pathophysiology (Newschaffer et al., 2007). As there is no available data on OXTR-ASD association in Bengali of Bangladesh (BEB) population, our research endeavored to assess the impacts of four OXTR polymorphisms (rs53576 and rs2254298: prominent and wellstudied; rs2228485 and rs23791: less studied), in the susceptibility of ASD. To our knowledge, this is the first study in Bangladesh and therefore, in the present investigation we are focusing on the relationship between Oxytocin receptor $(O X T R)$ gene polymorphism and ASD.

\section{Materials and Methods}

\subsection{Ethical clearance}

All procedures performed in this study involving human participants were under the ethical standard of Declaration of Helsinki, 1964. Ethical clearance for this study was taken from Chattagram Maa-O-Shishu General Hospital, Chittagong (ref: CMOSHMC/IRB/2018/6), Bangladesh. The written informed consent was obtained from the authority of respective institution and the legal guardian of all study participants, because maximum of the participants were children ( $<18$ years).

\subsection{Participants and diagnostic procedure}

Individuals, who fulfill the ASD diagnostic criteria set by DSM-5 (American Psychiatric Association, 2019) are selected as subjects, and healthy individuals were selected as control. By taking face to face interview from respective parents and caregivers of both 103 ASD individuals and control groups, the data were collected. Thus efforts were put to diagnose all the enrollees using a structured questionnaire (data not shown), and then an experienced child psychiatrist evaluated each patient's data in terms of diagnosis. ASD diagnosis was made when a subject had all of the three symptoms in social communication and social interaction domain or at least had two manifestations of the restricted, repetitive patterns of behavior, interests, or activities domain. In addition to the ASD severity criteria in DSM-5, Childhood Autism Rating Scale (CARS) (Schopler et al., 1980, 1988) was also used in diagnosis and rating of autism with a 15 -item scale consists of fourteen questions (each querying a discrete behavior and an additional question investigating the general impression about autism spectrum disorder) to determine the severity level of this disorder according to Rellini et al. (2004) and Ocakoğlu et al., (2018). 


\subsection{Sample collection}

Considering the fact of less positive response from ASD individual's family in our study, blood samples of 50 ASD individuals and 50 healthy controls (age, sex matched) were collected to obtain deoxyribonucleic acid (DNA). Participants and their families were informed about the process and the complications that may develop before the blood sampling procedure. Then, $2.0 \mathrm{ml}$ blood samples were taken in tubes containing tri-potassium ethylene diamine tetra acetic acid (K3EDTA) by expert phlebotomist experienced in working with ASD participants. Immediately after the sampling, obtained samples were delivered to the laboratory by maintaining cold chain where the genetic analysis was to be performed.

\subsection{DNA extraction}

Genomic DNA was extracted from collected blood samples by using PureLink ${ }^{\mathrm{TM}}$ Genomic DNA extraction kit (Invitrogen ${ }^{\mathrm{TM}}$, Thermofisher Scientific, MA, USA) according to the manufacturer's instructions.

\subsection{Genotyping}

Targeted four OXTR gene variants were amplified with polymerase chain reaction (PCR) using the primers listed in Table 1(a). Then the amplified products were genotyped by using PCR-RFLP method (Figure 1).

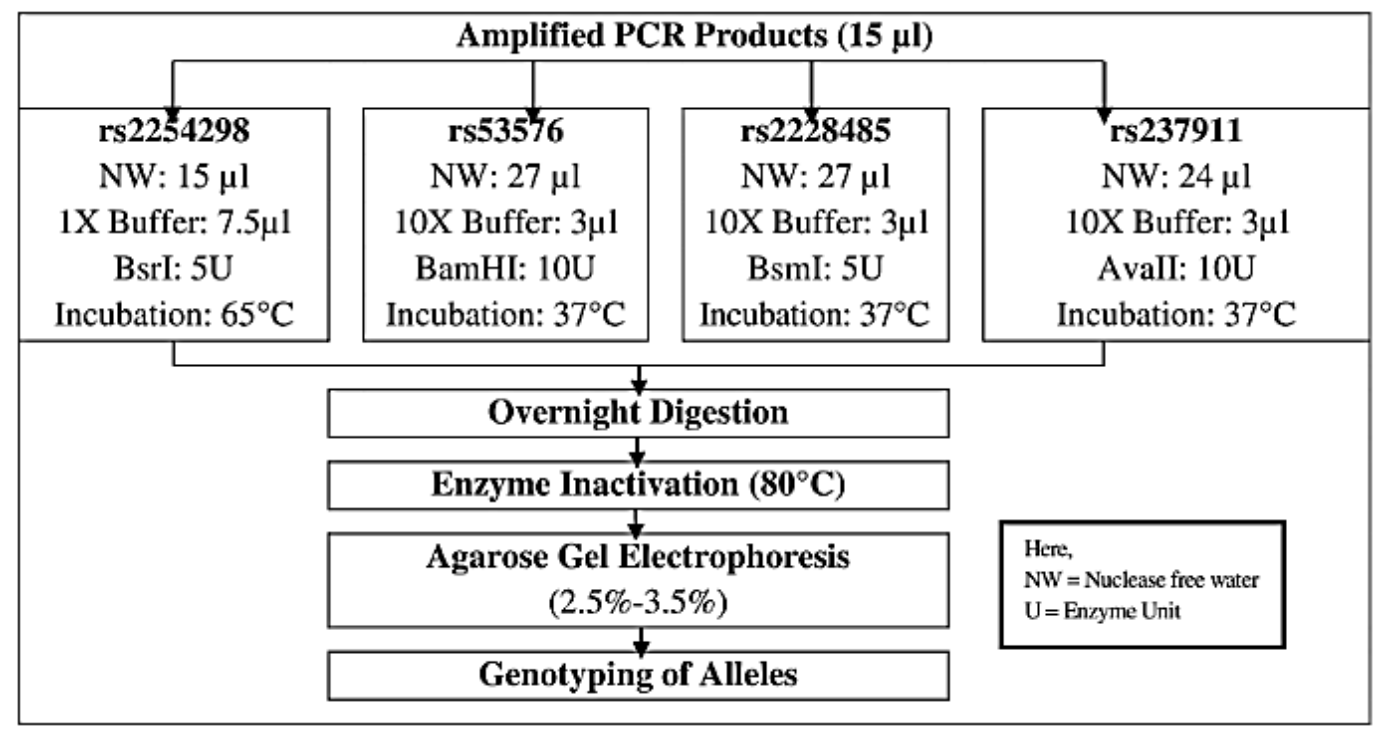

Figure 1. Flow chart of PCR-RFLP analysis.

The list of restriction enzyme was given in Table 1(b). Selected PCR products were sequenced (1st BASE Laboratories, Malaysia following Sanger method of DNA sequencing) and data was analyzed, where Single Nucleotide Polymorphisms (SNPs) was detected by SnapGene ${ }^{\circledR}$ Viewer tool (Version 4.2.2, from GSL Biotech; available at snapgene.com). The sequencing data was matched with the PCR-RFLP genotyping results.

Table 1(a). List of primers.

\begin{tabular}{lll}
\hline SNPs & Primer sequences $\left(\mathbf{5}^{\prime}\right.$-3' $^{\prime}$ ) & Product length $(\mathbf{b p})$ \\
\hline $\mathbf{r s 5 3 5 7 6}$ & GCCCACCATGCTCTCCACATC & 340 \\
$\mathbf{r s 2 2 5 4 2 9 8}$ & GCTGGACTCAGGAGGAATAGGGAC & \\
$\mathbf{r s 2 2 2 8 4 8 5}$ & TGAAAGCAGAGGTTGTGTGGACAGG & 307 \\
$\mathbf{r s 2 3 7 9 1 1}$ & AACGCCCACCCCAGTTTCTC & \\
& CCGTAAAGGGCTCGAAGG & 394 \\
& ACTTGACCAGGCGGCACA & 300 \\
\hline
\end{tabular}


Table 1(b). List of enzymes.

\begin{tabular}{|c|c|c|c|c|}
\hline SNPs & Product length (bp) & RFLP & & (bp) \\
\hline rs53576 & 340 & BamHI & $\begin{array}{l}\mathrm{G} \\
340\end{array}$ & $\begin{array}{l}\text { A } \\
230 / 110\end{array}$ \\
\hline rs2254298 & 307 & BsrI & $\begin{array}{l}\mathrm{A} \\
135 / 164 / 8\end{array}$ & $\begin{array}{l}\mathrm{G} \\
101 / 34 / 164 / 8\end{array}$ \\
\hline rs2228485 & 394 & BsmI & $\begin{array}{l}\mathrm{C} \\
394\end{array}$ & $\begin{array}{l}\text { T } \\
175 / 219\end{array}$ \\
\hline rs237911 & 300 & AvalI & $\begin{array}{l}\text { A } \\
300\end{array}$ & $\begin{array}{l}\text { G } \\
100 / 200\end{array}$ \\
\hline
\end{tabular}

\subsubsection{Allele and genotype frequencies calculation}

Allele and Genotype frequencies of the study population were calculated by using Hardy-Weinberg equation (Hardy, 1908) with a web program (http://scienceprimer.com/hardy-weinberg-equilibrium-calculator) and tested with the Chi-square $\left(\chi^{2}\right)$ test for all of the Single Nucleotide Polymorphisms (SNPs) under consideration. After that, the calculated allelic frequencies were compared with the allelic frequency of BEB population (data were retrieved from dbSNP and 1000 genome projects) (Siva, 2008).

\subsection{Statistical analysis}

Data obtained from this study underwent descriptive and inferential statistical analysis. Noncontinuous data were expressed as percentages, and the comparison of the data was performed by Chi-square $\left(\chi^{2}\right)$ test. All the statistical parameters were calculated by SPSS software version 16.0 (SPSS Inc., Chicago, IL, USA). For all the statistical analysis the level of significance was set at $\mathrm{p}<0.05$.

\section{Results}

Interestingly, from the genotyping analysis, the frequency of rs53576 AA genotype was significantly $(\mathrm{p}=0.027)$ higher (30\%) in the ASD compared to the control (12\%) group (Table 2). Consequently, our allelic frequency calculations (by using Hardy-weinberg equation) also showed that while the rs53576A allele acting as minor $(\mathrm{A}=0.410)$ in the control but major in the ASD $(\mathrm{A}=0.660$, Table 3$)$ which was also dissimilar from the calculated frequency of Bengali of Bangladesh (BEB) population (db SNP and 1000 genome projects). For the remaining SNPs (rs2254298, rs2228485, rs237911) the allelic frequency was quite similar with the calculated frequency for BEB population (Table 3). The summary of our findings is also listed on Table 2 and 3 and also in Figure 2, 3, 4, 5 and Figure 6 (a, b, c, d). To summarize, we have identified a particularly higher rs53576A allelic frequency in the studied ASD group.

Table 2. Summary of the genotyping results of four studied $O X T R$ variants and comparison with controls.

\begin{tabular}{llllll}
\hline $\begin{array}{l}\text { OXTR variants } \\
\text { (SNPs) }\end{array}$ & Genotype & $\begin{array}{l}\text { ASD } \\
(\mathbf{n = 5 0})\end{array}$ & $\begin{array}{l}\text { Controls } \\
(\mathbf{n = 5 0})\end{array}$ & $\begin{array}{l}\boldsymbol{\chi}^{\mathbf{2}} \\
\text { value }\end{array}$ & p value \\
\hline \multirow{3}{*}{ rs53576 } & GG & $18 \%(9)$ & $30 \%(15)$ & 1.974 & 0.160 \\
& AG & $52 \%(26)$ & $58 \%(29)$ & 0.364 & 0.546 \\
\hline \multirow{3}{*}{ rs2254298 } & AA & $30 \%(15)$ & $12 \%(6)$ & 4.882 & $0.027^{*}$ \\
& GG & $82 \%(41)$ & $76 \%(38)$ & 0.542 & 0.461 \\
& AG & $14 \%(7)$ & $16 \%(8)$ & 0.078 & 0.779 \\
rs2228485 & AA & $4 \%(2)$ & $8 \%(4)$ & 0.709 & 0.400 \\
& TT & $78 \%(39)$ & $70 \%(35)$ & 0.832 & 0.361 \\
& CT & $18 \%(9)$ & $20 \%(10)$ & 0.065 & 0.798 \\
rs237911 & CC & $4 \%(2)$ & $10 \%(5)$ & 1.382 & 0.239 \\
& AA & $62 \%(31)$ & $66 \%(33)$ & 0.174 & 0.677 \\
& AG & $38 \%(19)$ & $34 \%(17)$ & 0.174 & 0.676 \\
\hline
\end{tabular}

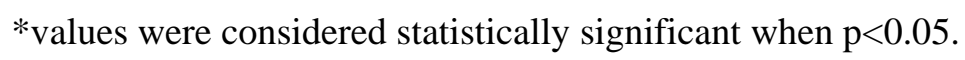


Table 3. OXTR variants allelic frequency calculations.

\begin{tabular}{|c|c|c|c|c|c|c|}
\hline SNPs & & Allele & A freq. & $\begin{array}{l}\text { A freq. of ref. } \\
\text { population (BEB) }\end{array}$ & Genotype & G freq. \\
\hline \multirow{6}{*}{ rs53576 } & ASD & $\mathbf{G}$ & 0.440 & \multirow{6}{*}{$\begin{array}{l}\text { G: } 0.5174 \\
\text { A: } 0.4826\end{array}$} & GG & 0.194 \\
\hline & $(\mathrm{n}=50)$ & & & & $\mathrm{AG}$ & 0.580 \\
\hline & & $\mathbf{A}$ & 0.660 & & $\mathrm{AA}$ & 0.435 \\
\hline & Control & $\mathbf{G}$ & 0.590 & & GG & 0.348 \\
\hline & $(\mathrm{n}=50)$ & & & & $\mathrm{AG}$ & 0.484 \\
\hline & & $\mathbf{A}$ & 0.410 & & AA & 0.168 \\
\hline \multirow{6}{*}{ rs2254298 } & ASD & G & 0.870 & \multirow{6}{*}{$\begin{array}{l}\text { G: } 0.7295 \\
\text { A: } 0.2705\end{array}$} & GG & 0.756 \\
\hline & $(\mathrm{n}=50)$ & & & & $\mathrm{AG}$ & 0.226 \\
\hline & & $\mathbf{A}$ & 0.130 & & $\mathrm{AA}$ & 0.016 \\
\hline & Control & G & 0.840 & & GG & 0.706 \\
\hline & $(\mathrm{n}=50)$ & & & & $\mathrm{AG}$ & 0.260 \\
\hline & & $\mathbf{A}$ & 0.160 & & AA & 0.026 \\
\hline \multirow{6}{*}{ rs2228485 } & ASD & $\mathbf{T}$ & 0.870 & \multirow{6}{*}{$\begin{array}{l}\text { T: } 0.9360 \\
\text { C: } 0.0640\end{array}$} & TT & 0.756 \\
\hline & $(\mathrm{n}=50)$ & & & & $\mathrm{CT}$ & 0.260 \\
\hline & & $\mathbf{C}$ & 0.130 & & $\mathrm{CC}$ & 0.017 \\
\hline & Control & $\mathbf{T}$ & 0.800 & & TT & 0.640 \\
\hline & $(\mathrm{n}=50)$ & & & & $\mathrm{CT}$ & 0.320 \\
\hline & & $\mathrm{C}$ & 0.200 & & $\mathrm{CC}$ & 0.040 \\
\hline \multirow{6}{*}{ rs237911 } & ASD & $\mathbf{A}$ & 0.810 & \multirow{6}{*}{$\begin{array}{l}\text { A: } 0.9128 \\
\text { G: } 0.0872\end{array}$} & AA & 0.657 \\
\hline & $(\mathrm{n}=50)$ & & & & $\mathrm{AG}$ & 0.307 \\
\hline & & $\mathbf{G}$ & 0.190 & & GG & 0.036 \\
\hline & Control & $\mathbf{A}$ & 0.830 & & AA & 0.689 \\
\hline & $(\mathrm{n}=50)$ & & & & AG & 0.282 \\
\hline & & G & 0.170 & & GG & 0.028 \\
\hline
\end{tabular}

$\mathrm{SNP}=$ Single Nucleotide polymorphism; A freq.=allele frequency; $\mathrm{G}$ freq. $=$ Genotype $\quad$ frequency; $\mathrm{BEB}=\mathrm{Bengali}$ of Bangladesh.

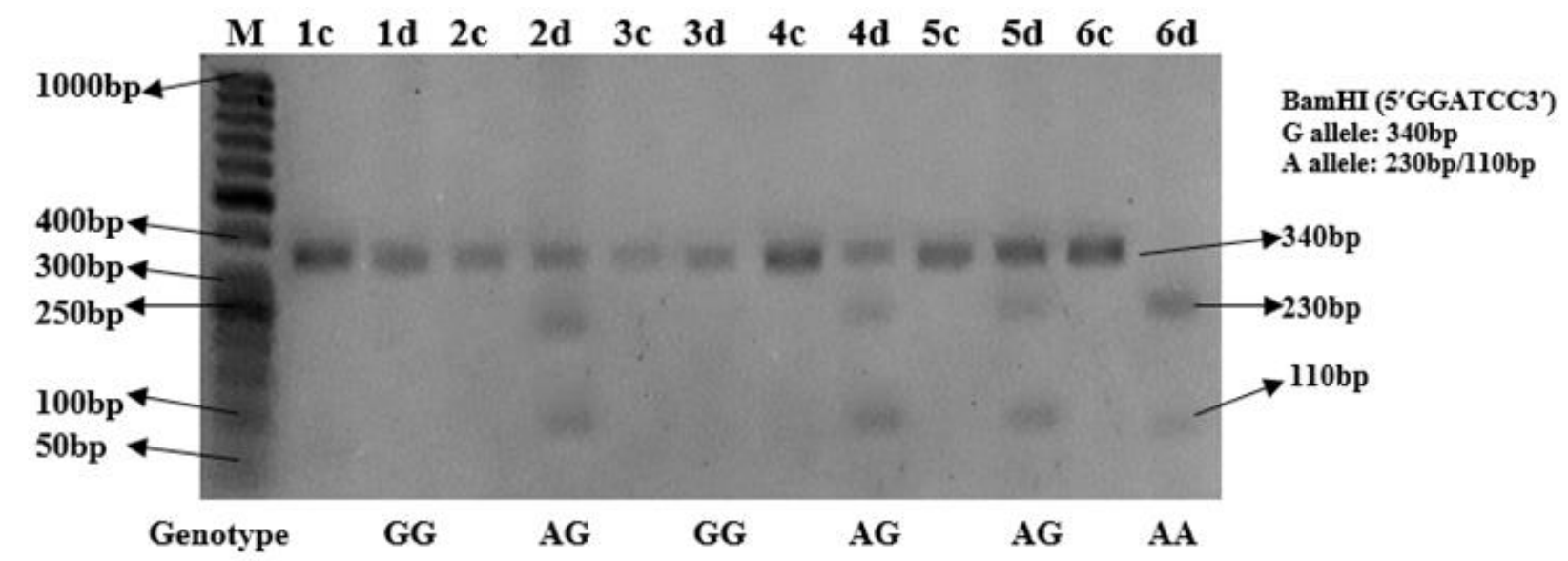

Figure 2. Genotyping of rs53576 by PCR-RFLP method. Here, $M=50 \mathrm{bp}$ DNA Ladder (Gene Ruler $^{\mathrm{TM}}$, Thermofisher Scientific), $\mathrm{c}=$ Undigested PCR product, $\mathrm{d}=$ Digested PCR product. Lane 1d, $3 \mathrm{~d}$ represents genotype $\mathrm{GG}$; lane $2 \mathrm{~d}, 4 \mathrm{~d}$ represents genotype $\mathrm{AG}$ and lane $6 \mathrm{~d}$ represents genotype AA. The digested products were visualized in $2.5 \%$ agarose gel. 


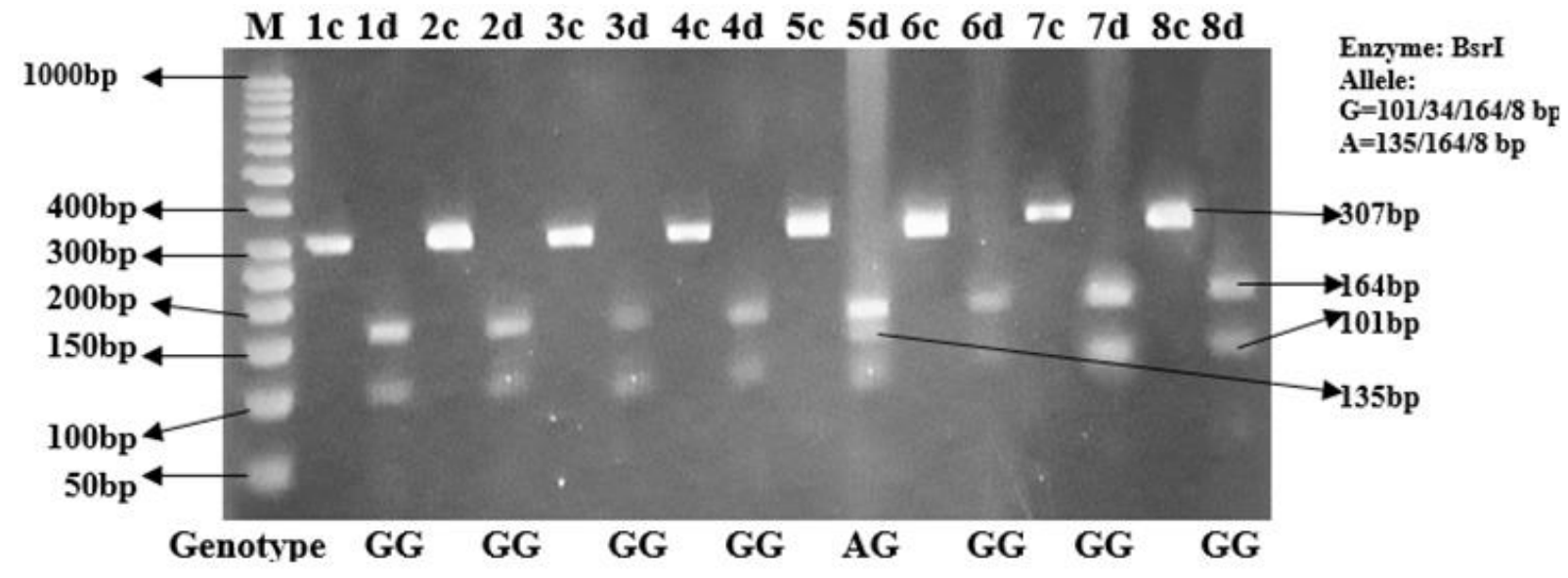

Figure 3. Genotyping of rs2254298 by PCR-RFLP method. Here, $\mathrm{M}=50 \mathrm{bp}$ DNA Ladder, $\mathrm{c}=$ Undigested PCR product, $\mathrm{d}=$ Digested PCR product. Lane 1d-4d and 6d-8d represents Genotype GG. Lane $5 \mathrm{~d}$ represents AG. The digested products were visualized in 3.5\% agarose gel.

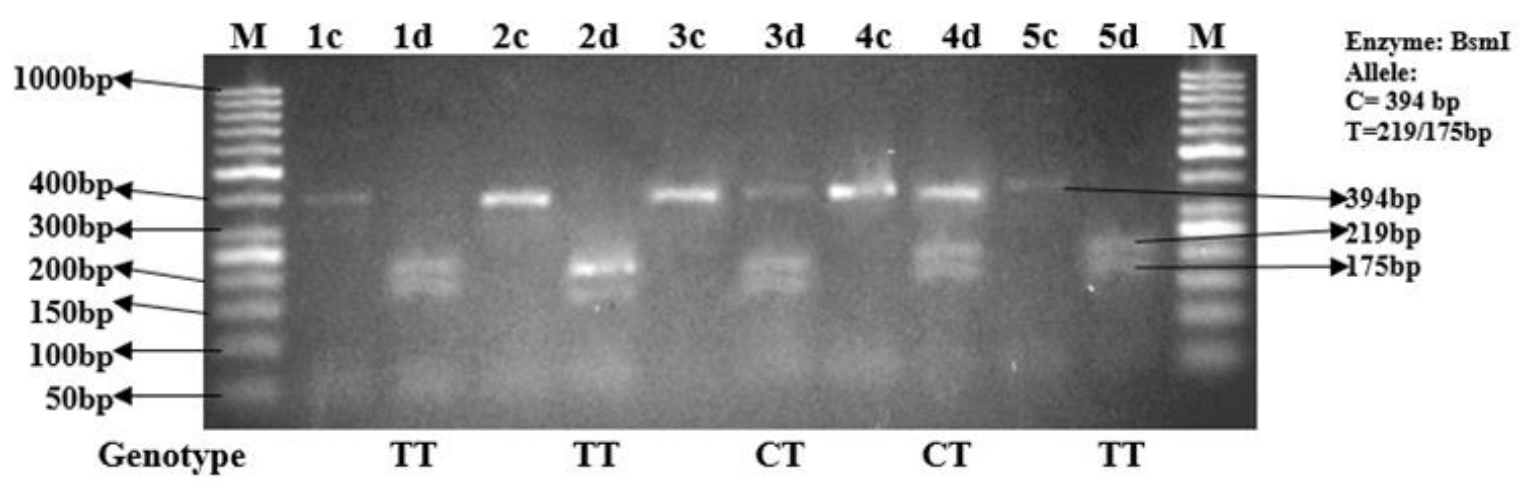

Figure 4. Genotyping of rs2228485 by PCR-RFLP method. Here, $\mathrm{M}=50 \mathrm{bp}$ DNA Ladder, $\mathrm{c}=$ Undigested PCR product, $\mathrm{d}=$ Digested PCR Product. Lane 1d, 2d, 5d represent genotype TT; lane $3 \mathrm{~d}, 4 \mathrm{~d}$ represents genotype CT. The digested PCR products were visualized in 3.0\% Agarose gel.

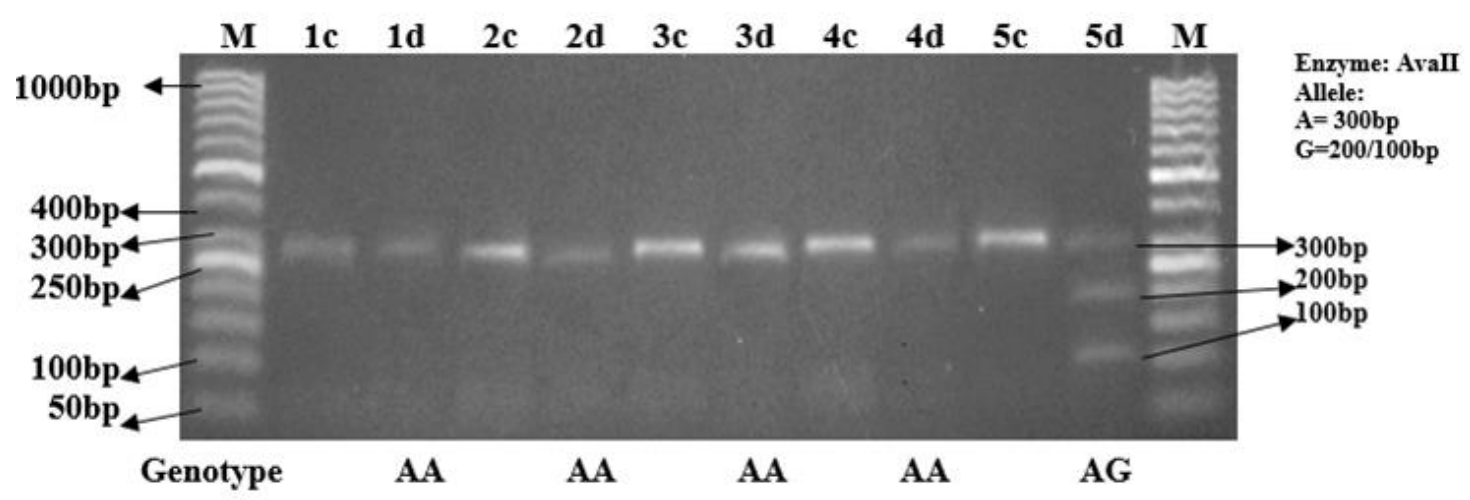

Figure 5. Genotyping of rs237911 by PCR-RFLP method. Here, $\mathrm{M}=50 \mathrm{bp}$ DNA Ladder, $\mathrm{c}=$ Undigested PCR product, $d=$ Digested PCR Product. Lane $1 \mathrm{~d}$ to $4 \mathrm{~d}$ represents Genotype AA. Lane $5 \mathrm{~d}$ represents AG. The digested products were visualized in $3.0 \%$ agarose gel. 


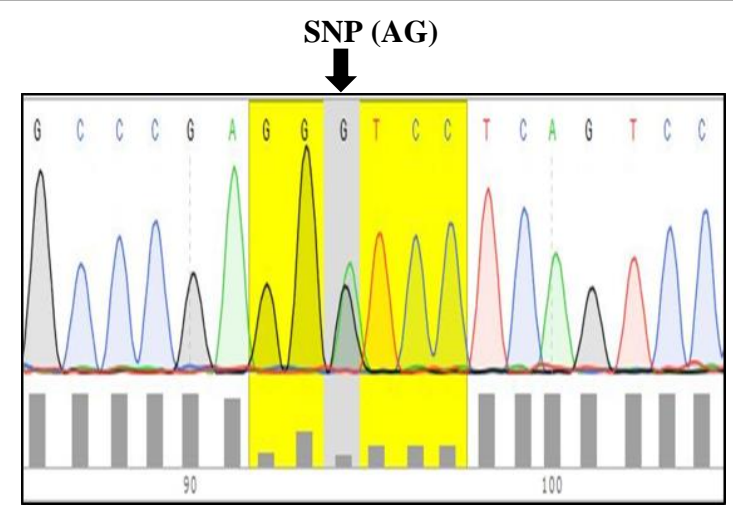

(a) $\mathbf{r s 5 3 5 7 6}$

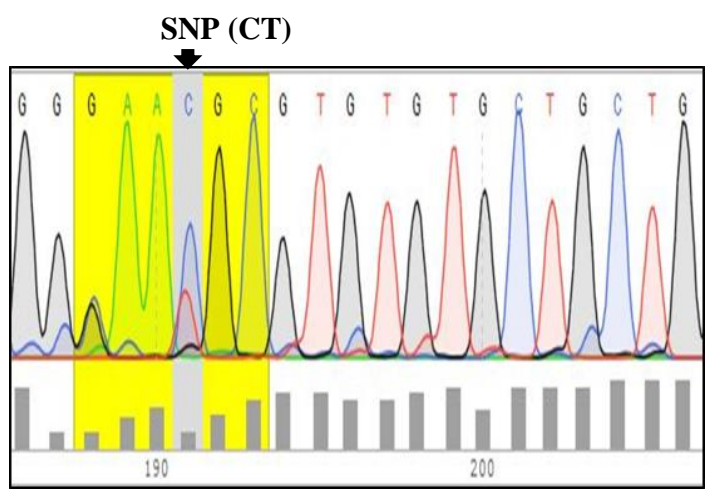

(c) $\mathbf{r s 2 2 2 8 4 8 5}$

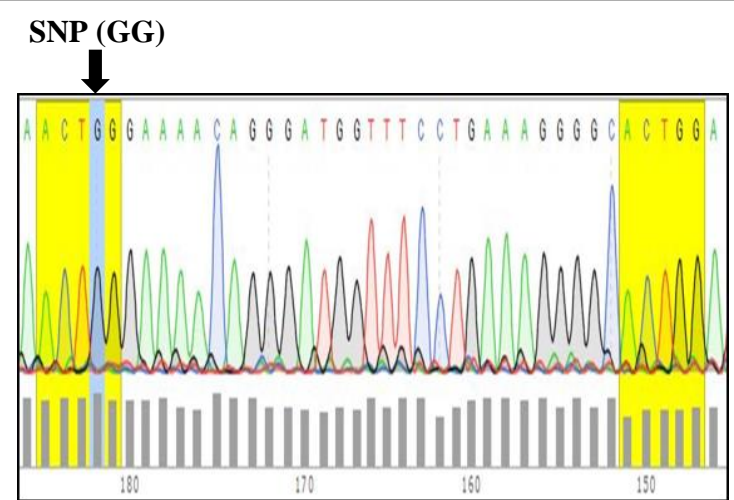

(b) rs2254298

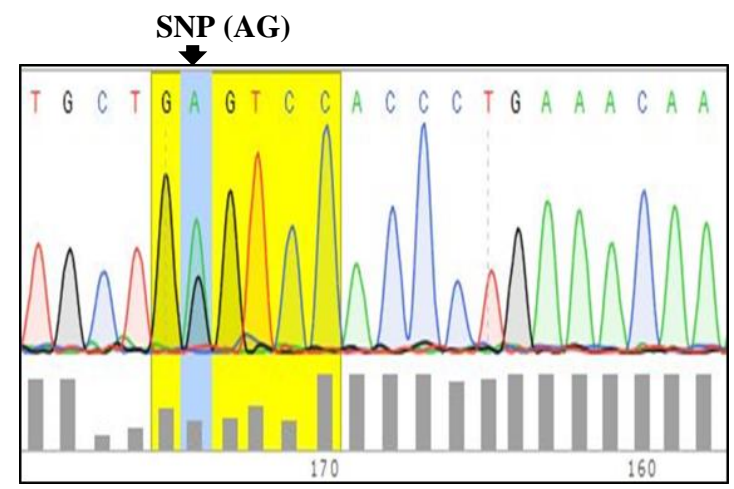

(d) rs237911

Figure 6 (a, b, c, d). Sequencing data.

\section{Discussion}

A group of conditions defined by qualitative abnormalities in reciprocal social interaction, distinctive patterns of communication and by a restricted, stereotyped, repetitive repertoire of interests and actions (WHO, 1992) was classified by ICD-10 as Autism Spectrum Disorder (ASD) under the Pervasive developmental disorders. Interest in the role of Oxytocin (OXT) hormone in the development of ASD has increased with the demonstration that this hormone plays an essential role in social attraction, affiliative behavior and bonding, as well as any disruption or change in this cascade, may lead to the development of social deficit (Greene et al., 2018; Busnelli and Chini, 2017; Hernandez, 2017; Olff et al., 2013). Failure of social adaptation on repeated exposure was seen in $O X T$ knockout mice supports the function of oxytocin in integrating social olfactory information and facilitating the consolidation of social memory (Young et al., 2002). Moreover, several studies have demonstrated that ASD participants tend to have low plasma oxytocin levels (Green et al., 2001) and intranasally administered oxytocin results in improved eye contact, social memory and better use of social information among individuals with high functioning ASD (Bethlehem et al., 2013; Andari et al., 2010; Hollander et al., 2007; 2003).

There is an ongoing debate in the current literature about the relation between Single Nucleotide Polymorphisms (SNPs) in the Oxytocin receptor (OXTR) gene and manifestation of social behaviors. Many studies have performed analyses in which they genotyped multiple SNPs and/or haplotypes, but the findings are quite divergent with cultural differences (Loparo and Waldman, 2015). Interestingly rs53576 is one of the most studied SNPs which has shown to affect social behavior and homozygous AA has a significant contribution in the development of ASD in Chinese population (Wu et al., 2005), however no association of rs53576 was also found in Caucasian and Japanese population (Campbell et al., 2011; Liu et al., 2010). Furthermore, rs53576GG homozygotes had higher general sociality compared to A allele carriers (Li et al., 2015). In another study investigating the link between rs53576 and trust has shown that GG homozygous males were more trusting than AA males, but this pattern was not found for females (Nishina et al., 2015). A population-based study in Asian 
and European population, it is reported that $O X T R$ variant $\mathrm{rs} 53576 \mathrm{G}$ allele is associated with better empathy characteristics in individuals than the A allele (Gong et al., 2017). It has been proved that rs53576 genotype GG and parental bonding history interact in influencing social development of infants (Truzzi et al., 2018). This SNP (A/G) is located in the third intronic region of the OXTR gene in chromosome 3, which is $6929 \mathrm{bp}$ downstream from the transcription start (TrxSt) site (Campbell et al., 2011). Introns in contemporary species fulfill a broad spectrum of functions and are involved in virtually every step of mRNA processing (Carmel and Chorev, 2012) but how rs53576A allele play a prominent role in social bonding by influencing the OXT-OXTR cascade is still unknown.

In molecular analysis of our study, the association of risk genotype rs53576 (AA) with ASD was statistically significant $(30 \%, \mathrm{p}<0.05)$ (Table 2). Though ' $\mathrm{A}$ ' allele was minor $(0.410)$ in our studied control population and reference BEB population, the frequency of this allele was major (0.66) in the studied ASD population (Table 3 ). The absence of this risk allele rs53576A in the other ASD participants explains that the presence of this risk allele rs53576A is not the only risk factor of ASD. There are several genetic and environmental conditions, which may lead to the development of ASD, either individually or combined (Di Napoli et al., 2014).

Consistent with the hypothesis that genetic variation at OXTR is possibly associated with differential susceptibility, carriers of the AG or AA genotype of the rs2254298 SNP are more vulnerable to developing a psychiatric condition, including autism (Brüne, 2012; Jacob et al., 2007) depression and anxiety disorders (Chen and Johnson, 2012; Thompson et al., 2011; Costa et al., 2009; Lucht et al., 2009). The first report about the positive association of rs2254298A allele with ASD was found in the Chinese population (Wu et al., 2005), and another study in Japanese population also showed consistency with this results (Liu et al., 2010). On the contrary, concerning autism as a disorder with a core deficit in social communication, over-transmission of the $\mathrm{G}$ allele in the intronic SNP rs2254298 found in Caucasian autistic subjects (Jacob et al., 2007). The G allele was hence linked to less friendly behavior, and thus, the A allele is suggested to be associated with prosocial behavior (Lerer et al., 2008). In our studied population, we found no significant association between rs 2254298 polymorphism and ASD (Table 2). The major allele in our studied ASD population was rs2254298G (0.87, Table 3), which is consistent with the findings of Caucasian and Jewish population but with Chinese and Japanese population. So, the SNP rs2254298 may not play any role in the development of ASD in our studied population.

On the other hand, haplotypes involving OXTR rs2228485 showed an excess transmission from parents to affected offspring (Wu et al., 2005) with autism. In two separate studies, rs2228485 did not show any significant associations with ASD (Kelemenova et al., 2010; Chakrabarti et al., 2009). The rs2228485 is a synonymous coding SNP located in exon 3 of the OXTR gene (Algovik et al., 2010) which encodes amino acids of the oxytocin receptor (Gimpl and Fahrenholz, 2001). There is accumulating evidence that synonymous SNPs can affect splicing or messenger-ribonucleic-acid (mRNA) stability, thereby altering the gene products (Chamary et al., 2006). This line of arguing suggests a biological rationale of rs2228485. However, in our studied population, no significant association was found for any of the genotype (TT/CC/CT) (Table 2). The major allele was rs2228485T (Table 3) in both of the ASD and control population.

Being located in the promoter region rs237911 (A>G) polymorphism is a potential candidate but no positive association with ASD has been found in any population (Wu et al., 2005). In our studied population, rs237911 A allele has been found as major allele in both ASD and control population (Table 3) and no significant association was found with ASD (Table 2).

In summary, the OXTR SNP 'rs53576A' allele may be the risk allele for BEB population, which is consistent with the previous findings in Chinese (Wu et al., 2005). Further studies of OXTR with larger sample size are recommended to analyze the real causal variants of the BEB population. Expected therapeutic resource for ASD can be oxytocin since this neuropeptide can modulate human social behavior cognition (Yamasue et al., 2016; Guastella et al., 2015), even though some controversies remains about its effectiveness, doses, treatment duration, administration route and timing of starting the treatment (Parker et al., 2017; Kosaka et al., 2016; Okamoto et al., 2016; Preti et al., 2014). We conclude that other untested OXTR polymorphisms may combinedly contribute to the development of ASD, thus further investigation on OXTR SNPs and clinical trials with oxytocin in young children should examine functional domain beyond those related to social behaviors.

\section{Conclusions}

This comprehensive study put light on association of oxytocin receptor (OXTR) gene variants with Autism Spectrum Disorder (ASD). To understand the genetic basis and the role of OXTR SNPs in ASD development, we have done the PCR-RFLP analysis and Sanger sequencing to genotype our studied BEB population; thus we found that OXTR SNP rs53576A allele significantly associated with ASD, which is consistent with previous 
study in Chinese. Understanding how genetic variation may impact the ASD development is important for identifying novel biological treatments like intranasal oxytocin administration or etc.

\section{Acknowledgements}

This study was partially supported by Research \& Publication Office of the University of Chittagong, Bangladesh (Ref. 6167/2018; fiscal year 2017-2018) and Ministry of Science and Technology, Bangladesh (Special Allocation for Science and Technology, GO no. 210 BS; fiscal year 2019-2020). This research was done in the 'Molecular Biology Laboratory' of the Department of Genetic Engineering and Biotechnology, University of Chittagong. We are grateful to all the autism schools and centers* as well as the ASD individual's parents who actively participated in this study. Special thanks to Professor Basana Rani Muhuri, M.B.B.S; FCPS (Pediatrics), Department of Pediatric Nephrology, Chittagong Medical College and Nasmin Hayat Ivy, Psychologist, Institute of Autism and Child Development Centre, Chattogram Maa-O-Shishu General Hospital, Agrabad, Chittagong-4100, Bangladesh for their support during sampling.

*Proyash Chittagong; Dream Star Autism Academy; Autism O Shisho Bikash Kendro (CMOSH); Nishpap Autism Foundation; Matrisneha Autism Children Academy; Ashar Alo School and Rehabilitation Center.

\section{Conflict of interest}

None to declare.

\section{References}

Algovik M, K Kivinen, H Peterson, M Westgren and J Kere, 2010. Genetic evidence of multiple loci in dystocia-difficult labour. BMC Med. Gen., 11: 105.

American Psychiatric Association. Accesed on 04/04/2019. Available at: https://www.psychia try.org/ psychiatrists/practice/dsm

Andari E, JR Duhamel, T Zalla, E Herbrecht, M Leboyer and A Sirigu, 2010. Promoting social behavior with oxytocin in high-functioning autism spectrum disorders. Proc. Natl. Acad. Sci. U.S.A., 107: 4389-4394.

Betancur C, 2011. Etiological heterogeneity in autism spectrum disorders: more than 100 genetic and genomic disorders and still counting. Brain Research, 1380: 42-77.

Bethlehem RA, J van Honk, B Auyeung and S Baron-Cohen, 2013. Oxytocin, brain physiology, and functional connectivity: a review of intranasal oxytocin fMRI studies. Psychoneuroendo., 38: 962-974.

Busnelli M and B Chini, 2017. Molecular basis of oxytocin receptor signalling in the brain: what we know and what we need to know. InBehavioral Pharmacology of Neuropeptides: Oxytocin. (pp. 3-29). Springer. Cham.

Campbell DB, D Datta, ST Jones, EB Lee, JS Sutcliffe, EA Hammock and P Levitt, 2011. Association of oxytocin receptor (OXTR) gene variants with multiple phenotype domains of autism spectrum disorder. J. Neuro. Dev. Dis., 3: 101.

Carmel L and M Chorev, 2012. The function of introns. Front. Gen., 3: 55.

Center for Disease Control (CDC). Accessed on 04/04/2019. Available: https://www.cdc.gov/ncb ddd/autism/addm.html

Chakrabarti B, F Dudbridge, L Kent, S Wheelwright, G Hill-Cawthorne, C Allison, S Banerjee-Basu and S Baron-Cohen, 2009. Genes related to sex steroids, neural growth, and social-emotional behavior are associated with autistic traits, empathy, and Asperger syndrome. Autism. Research., 2: 157-77.

Chamary JV, JL Parmley and LD Hurst, 2006. Hearing silence: non-neutral evolution at synonymous sites in mammals. Nat. Rev. Gen., 7: 98.

Daily Prothom Alo, Bangladesh. Accessed on 2/02/2019. Available: https://en.prothom alo.Com/ar chive/2018 09-10

Di Napoli A, V Warrier, S Baron-Cohen and B Chakrabarti, 2014. Genetic variation in the oxytocin receptor (OXTR) gene is associated with Asperger Syndrome. Mol. Autism., 5: 48.

Ebstein RP, S Israel, E Lerer, F Uzefovsky, I Shalev, I Gritsenko, M Riebold, S Salomon and N Yirmiya, 2009. Arginine vasopressin and oxytocin modulate human social behavior. Annals. NewYork. Aca. Sci., 1167: 87102.

Ferguson JN, LJ Young, EF Hearn, MM Matzuk, TR Insel and JT Winslow, 2000. Social amnesia in mice lacking the oxytocin gene. Nat. Gen., 25: 284.

Freitag CM, 2007. The genetics of autistic disorders and its clinical relevance: a review of the literature. Mol. Psychi., 12: 2.

Friedlander E, N Yirmiya, E Laiba, A Harel-Gadassi, M Yaari, O Feldstein, D Mankuta and S Israel, 2019. 
Cumulative Risk of the Oxytocin Receptor Gene Interacts with Prenatal Exposure to Oxytocin Receptor Antagonist to Predict Children's Social Communication Development. Autism. Research. Apr 26.

Gimpl G and F Fahrenholz, 2001. The oxytocin receptor system: structure, function, and regulation. Physio. Reviews, 81: 629-683.

Greene RK, M Spanos, C Alderman, E Walsh, J Bizzell, MG Mosner, JL Kinard, GD Stuber, T Chandrasekhar, LC Politte and L Sikich, 2018. The effects of intranasal oxytocin on reward circuitry responses in children with autism spectrum disorder. J. Neurodev. Dis., 10: 12.

Green L, D Fein, C Modahl, C Feinstein, L Waterhouse and M Morris, 2001. Oxytocin and autistic disorder: alterations in peptide forms. Bio. Psychiatry., 50: 609-613.

Gong P, H Fan, J Liu, X Yang, K Zhang and X Zhou, 2017. Revisiting the impact of OXTR rs53576 on empathy: A population-based study and a meta-analysis. Psychoneuroendo., 80: 131-136.

Guastella AJ, KM Gray, NJ Rinehart, GA Alvares, BJ Tonge, IB Hickie, CM Keating, C Cacciotti-Saija and SL Einfeld, 2015. The effects of a course of intranasal oxytocin on social behaviors in youth diagnosed with autism spectrum disorders: a randomized controlled trial. J. Child. Psycho. Psychi., 56: 444-452.

Hardy GH, 1908. Mendelian proportions in a mixed population. Classic papers in genetics. Prentice-Hall, Inc.: Englewood Cliffs, NJ. 1908: 60-62.

Harris JC, 2016. The origin and natural history of autism spectrum disorders. Nat. Neurosci., 19: 1390.

Heinrichs M, B von Dawans and G Domes, 2009. Oxytocin, vasopressin, and human social behavior. Front. Neuroendocri., 30: 548-557.

Hernandez LM, K Krasileva, SA Green, LE Sherman, C Ponting, R McCarron, JK Lowe, DH Geschwind, SY Bookheimer and M Dapretto, 2017. Additive effects of oxytocin receptor gene polymorphisms on reward circuitry in youth with autism. Mol. Psychi., 22: 1134.

Hollander E, J Bartz, W Chaplin, A Phillips, J Sumner, L Soorya, E Anagnostou and S Wasserman, 2007. Oxytocin increases retention of social cognition in autism. Bio. Psychi., 61: 498-503.

Hollander E, S Novotny, M Hanratty, R Yaffe, CM DeCaria, BR Aronowitz and S Mosovich, 2003. Oxytocin infusion reduces repetitive behaviors in adults with autistic and Asperger's disorders. Neuropsychopharma., 28: 193.

Jacob S, CW Brune, CS Carter, BL Leventhal, C Lord and EH Cook Jr, 2007. Association of the oxytocin receptor gene (OXTR) in Caucasian children and adolescents with autism. Neurosci. Letters., 417: 6-9.

Kelemenova S, E Schmidtova, A Ficek, P Celec, A Kubranska and D Ostatnikova, 2010. Polymorphisms of candidate genes in Slovak autistic patients. Psychi. Gen., 20: 137-139.

Kosaka H, Y Okamoto, T Munesue, H Yamasue, K Inohara, T Fujioka, T Anme, M Orisaka, M Ishitobi, M Jung and TX Fujisawa, 2016. Oxytocin efficacy is modulated by dosage and oxytocin receptor genotype in young adults with high-functioning autism: a 24-week randomized clinical trial. Translation. Psychi., 6: e872.

Lakatosova S, L Dudova, A Pivovarciova, V Husarova, K Babinska, A Kubranska and D Ostatnikova, 2013. Association with autism of two polymorphisms in gene encoding oxytocin receptors in slovakia. Autism, 3: 121.

Lerer E, S Levi, S Salomon, A Darvasi, N Yirmiya and RP Ebstein, 2008. Association between the oxytocin receptor (OXTR) gene and autism: relationship to Vineland Adaptive Behavior Scales and cognition. Mol. Psychi., 13: 980.

Lichtenstein P, E Carlström, M Råstam, C Gillberg and H Anckarsäter, 2010. The genetics of autism spectrum disorders and related neuropsychiatric disorders in childhood. American. J. Psychi., 167: 1357-1363.

Li J, Y Zhao, R Li, LS Broster, C Zhou and S Yang, 2015. Association of oxytocin receptor gene (OXTR) rs53576 polymorphism with sociality: a meta-analysis. PLOS One, 10: e0131820.

Liu X, Y Kawamura, T Shimada, T Otowa, S Koishi, T Sugiyama, H Nishida, O Hashimoto, R Nakagami, M Tochigi and T Umekage, 2010. Association of the oxytocin receptor (OXTR) gene polymorphisms with autism spectrum disorder (ASD) in the Japanese population. J. Human. Gen., 55: 137.

LoParo D and ID Waldman, 2015. The oxytocin receptor gene (OXTR) is associated with autism spectrum disorder: a meta-analysis. Mol. Psychi., 20: 640.

Montag C, C Sindermann, M Melchers, S Jung, R Luo, B Becker, J Xie, W Xu, AJ Guastella and KM Kendrick, 2017. A functional polymorphism of the OXTR gene is associated with autistic traits in Caucasian and Asian populations. American. J. Med. Gen. Part B: Neuropsychi. Gen., 174: 808-816.

Newschaffer CJ, LA Croen, J Daniels, E Giarelli, JK Grether, SE Levy, DS Mandell, LA Miller, J Pinto-Martin, J Reaven and AM Reynolds, 2007. The epidemiology of autism spectrum disorders. Annu. Rev. Public. Health, 28: 235-258.

Nishina K, H Takagishi, M Inoue-Murayama, H Takahashi and T Yamagishi, 2015. Polymorphism of the 
oxytocin receptor gene modulates behavioral and attitudinal trust among men but not women. PloS One, 10: e0137089.

Norbury CF and A Sparks, 2013. Difference or disorder? Cultural issues in understanding neurodevelopmental disorders. Dev. Psycho., 49: 45.

Ocakoğlu FT, S Köse, B Özbaran and H Onay, 2018. The oxytocin receptor gene polymorphism-rs237902-is associated with the severity of autism spectrum disorder: a pilot study. Asian. J. Psychi., 31: 142-149.

Okamoto Y, M Ishitobi, Y Wada and H Kosaka, 2016. The potential of nasal oxytocin administration for remediation of autism spectrum disorders. CNS. \& Neuro. Disor.-Drug. Targets, 15: 564-577.

Olff M, JL Frijling, LD Kubzansky, B Bradley, MA Ellenbogen, C Cardoso, JA Bartz, JR Yee and M van Zuiden, 2013. The role of oxytocin in social bonding, stress regulation and mental health: an update on the moderating effects of context and interindividual differences. Psychoneuroendocri., 38: 1883-1894.

Parker KJ, JP Garner, RA Libove, SA Hyde, KB Hornbeak, DS Carson, CP Liao, JM Phillips, JF Hallmayer and AY Hardan, 2014. Plasma oxytocin concentrations and OXTR polymorphisms predict social impairments in children with and without autism spectrum disorder. Proceedings. Nat. Aca. Sci., 111: 12258-12263.

Parker KJ, O Oztan, RA Libove, RD Sumiyoshi, LP Jackson, DS Karhson, JE Summers, KE Hinman, KS Motonaga, JM Phillips and DS Carson, 2017. Intranasal oxytocin treatment for social deficits and biomarkers of response in children with autism. Proceedings. Nat. Aca. Sci., 114: 8119-8124.

Preti A, M Melis, S Siddi, M Vellante, G Doneddu and R Fadda, 2014. Oxytocin and autism: a systematic review of randomized controlled trials. J. Child. Adolescent. Psychopharma., 24: 54-68.

Rellini E, D Tortolani, S Trillo, S Carbone and F Montecchi, 2004. Childhood Autism Rating Scale (CARS) and Autism Behavior Checklist (ABC) correspondence and conflicts with DSM-IV criteria in diagnosis of autism. J. Autism. Dev. Dis., 34: 703-708.

Reuter M, C Montag, S Altmann, F Bendlow, C Elger, P Kirsch, A Becker, S Schoch-McGovern, M Simon, B Weber and A Felten, 2017. Functional characterization of an oxytocin receptor gene variant (rs2268498) previously associated with social cognition by expression analysis in vitro and in human brain biopsy. Social. Neurosci., 12: 604-611.

Ribeiro LD, P Vargas-Pinilla, DB Kappel, D Longo, J Ranzan, MM Becker, R dos Santos Riesgo, L SchulerFaccini, T Roman and JB Schuch, 2018. Evidence for association between OXTR gene and ASD clinical phenotypes. J. Mol. Neurosci., 65: 213-221.

Schopler E, RJ Reichler, RF DeVellis and K Daly, 1980. Toward objective classification of childhood autism: Childhood Autism Rating Scale (CARS). J. Autism. Dev. Dis., 10: 91-103.

Schopler E, RJ Reichler and BR Renner, 1988. The Childhood Autism Rating Scale (CARS). Los Angeles: Western Psychological Services. J. Autism. Dev. Dis., 10: 91-103.

Siva N, 2008. 1000 Genomes project.

Skuse DH, A Lori, JF Cubells, I Lee, KN Conneely, K Puura, T Lehtimäki, EB Binder and LJ Young, 2014. Common polymorphism in the oxytocin receptor gene (OXTR) is associated with human social recognition skills. Proceedings of the Nat. Aca. Takayanagi. Sci., 111: 1987-1992.

Tops S, U Habel and S Radke, 2019. Genetic and Epigenetic Regulatory Mechanisms of the Oxytocin Receptor Gene (OXTR) and the (Clinical) implications for social behavior. Hormones. Behav., 108: 84-93.

Truzzi A, J Poquérusse, P Setoh, K Shinohara, MH Bornstein and G Esposito, 2018. Oxytocin receptor gene polymorphisms (rs53576) and early paternal care sensitize males to distressing female vocalizations. Dev. Psychobio., 60: 333-339.

Volkmar FR, C Lord, A Bailey, RT Schultz and A Klin, 2004. Autism and pervasive developmental disorders. J. Child. Psycho. Psychi., 45: 135-170.

World Health Organization, 1992. The ICD-10 classification of mental and behavioural disorders: clinical descriptions and diagnostic guidelines. Geneva: World Health Organization.

Wu S, M Jia, Y Ruan, J Liu, Y Guo, M Shuang, X Gong, Y Zhang, X Yang and D Zhang, 2005. Positive association of the oxytocin receptor gene (OXTR) with autism in the Chinese Han population. Bio. Psychi., 58: 74-77.

Yamasue H, 2016. Promising evidence and remaining issues regarding the clinical application of oxytocin in autism spectrum disorders. Psychi. Clinical. Neurosci., 70: 89-99.

Young LJ, LJ Pitkow and JN Ferguson, 2002. Neuropeptides and social behavior: animal models relevant to autism. Mol. Psychi., 7: S38. 